\title{
Ação inversora do destino dos pobres Um estudo do Salmo 113
}

\author{
Matthias Grenzer
}

\section{Introdução}

Os escritos bíblicos destacam, de forma proeminente, uma determinada ação do Deus de Israel: o SENHOR age em favor dos mais necessitados. Mais ainda: o SENHOR propõe-se a libertar os miseráveis de seus opressores e de suas situações de vida indignas, querendo inverter, integralmente, o destino deles. Imagina-se até ser justamente esta a ação divina que distingue o Deus de Israel de supostos outros deuses (cf. S1 82).

Neste sentido, a ação de Deus em favor dos pobres ganha centralidade nas mais diversas tradições bíblicas, ao marcar presença nas narrativas que contam, teologicamente avaliada, a história do povo de Deus, ao ocupar as tradições jurídicas do Antigo Israel e ao inspirar os discursos proféticosapienciais. O mesmo vale para as "orações" contidas nas Sagradas Escrituras. Cultiva-se, pois, nelas uma espiritualidade intimamente preocupada com o destino dos pobres e com a justiça a ser feita a eles por Deus.

Todavia, o que foi dito agora de forma mais livre necessita de verificação. Por isso, proponho-me, neste artigo, apresentar um estudo literárioteológico do Salmo 113. Literário porque o texto é uma composição artística. $\mathrm{O}$ uso da linguagem acontece de forma planejada. Diversos elementos estilísticos ajudam para que as coisas sejam ditas de forma mais chamativa e clara. O estudo teológico, por sua vez, dedica-se ao conteúdo do poema e insiste na descrição exata do pensamento que o texto promove a respeito de Deus. 
Seja dito ainda de antemão que o Salmo 113, ao abrir o "Halel Egípcio", ocupa um lugar de destaque no Saltério. Trata-se da unidade literária formada pelo conjunto dos Salmos 113-118. ${ }^{1}$ Essas orações ganharam uma importância particular na vida espiritual do povo de Deus. Ao pensar na época do Segundo Templo, o qual existiu em Jerusalém entre os anos 515 a.C. e 70 d.C., verifica-se, na base dos escritos rabínicos, o uso do "Halel Egípcio" no Templo, nas sinagogas e em casa:

“Todo 'Halel Egípcio' é cantado, na sinagoga, nos dias de festa de Sucot (Tendas) e na festa de Chanucá. [...] Igualmente, o 'Halel Egípcio' é cantado inteiramente no $1^{\circ}\left(\mathrm{e} 2^{\circ}\right)$ dia(s) da festa semanal da Páscoa; no Templo, durante o abatimento dos cordeiros pascais. Também o Seder em casa, na noite da Páscoa, é acompanhado pelo 'Halel'. É cantado, durante a refeição, em duas partes: Salmos 113-114 antes da refeição e Salmos 115-118 depois da refeição". ${ }^{2}$

Em relação ao uso do "Halel Egípcio" no Seder, confira também a anotação dos evangelistas Mateus e Marcos, quando narram que, ao terminarem a ceia, Jesus e os apóstolos cantaram hinos (Mc 14,26; Mt 26,30).

\section{Tradução e estrutura do Salmo 113}

Seja apresentada, por primeiro, uma tradução do poema como um todo, o qual, originalmente, foi escrito em hebraico. Embora a tradução já espelhe os resultados dos estudos posteriores, vale lembrar de que todo processo de compreensão de um texto literário se dá com a leitura repetida dele.

Aproveito a oportunidade para apresentar o S1 113 logo de forma estruturada. Facilmente pode-se perceber que a "fórmula de louvor" — veja a expressão Aleluia (= Louvai o SENHOR!) em v. 1a.9c: - abre e fecha o poema, criando, dessa forma, uma inclusão ou moldura em torno do poema. ${ }^{3}$

De resto, a estrutura do Sl 113 é marcada por três estrofes (v. 1b-3.46.7-9b). Em princípio, cada estrofe é composta por três frases, sendo que cada uma delas apresenta um paralelismo formado por dois elementos.

\footnotetext{
${ }^{1}$ Veja a "arquitetura do Livro dos Salmos" em: Erich ZENGER e outros, Einleitung in das Alte Testament, p. 356.

${ }^{2}$ Jutta SCHRÖTEN. Entstehung, Komposition und Wirkungsgeschichte des 118. Psalms, p. 139.

${ }^{3}$ Em vista da "fórmula de louvor", cf. Klaus SEYBold, Poetik der Psalmen, p. 302s.
} 
1a Aleluia! [= Louvai o SENHOR!]

1b Louvai, ó servos do SENHOR,

1c louvai o nome do SENHOR!

2a Seja bendito o nome do SENHOR,

$2 \mathrm{~b} \quad$ desde agora e para sempre!

3a Do nascer do sol até seu poente,

$3 \mathrm{~b}$ seja louvado o nome do SENHOR!

4a O SENHOR é quem se eleva sobre todas as nações,

$4 \mathrm{~b} \quad$ sua glória está sobre os céus.

5a Quem é como o SENHOR, nosso Deus

$5 \mathrm{~b} \quad$ - que se enaltece para assentar-se

6a e se abaixa para ver -,

$6 \mathrm{~b} \quad$ nos céus e na terra?

7a É quem levanta o necessitado do pó:

$7 \mathrm{~b}$ do lixo, eleva o pobre,

8a a fim de fazê-lo assentar-se junto aos nobres,

$8 \mathrm{~b} \quad$ junto aos nobres de seu povo.

9a É quem deixa a estéril da casa assentar-se,

$9 \mathrm{~b} \quad$ como alegre mãe de filhos.

9c Aleluia! [= Louvai o SENHOR!]

\section{Convite de louvor ao nome do SENHOR}

A primeira frase (v. 1b.c) na primeira estrofe (v. 1b-3b) apresenta um paralelismo que nasce da repetição do imperativo do verbo louvar. Os dois complementos, por sua vez, indicam quem deve louvar (v. 1b) e o que deve ser louvado (v. 1c):
v. $1 \mathrm{~b}$ :
Louvai, ó servos do SENHOR,
v. 1c: louvai o nome do SENHOR!

As outras duas frases da primeira estrofe (v. 2a.b e v. 3a.b) formam uma estrutura concêntrica, em forma de um "quiasmo" com centro duplo:
v. 2a:
Seja bendito o nome do SENHOR,
v. $2 b$ : desde agora e para sempre!
v. 3a:
Do nascer do sol até seu poente,
v. $3 b$ : seja louvado o nome do SENHOR! 
Os elementos exteriores (v. 2a.3b) são paralelos por ambos apresentarem um particípio passivo (Pual), no masculino do singular - cf. bendito

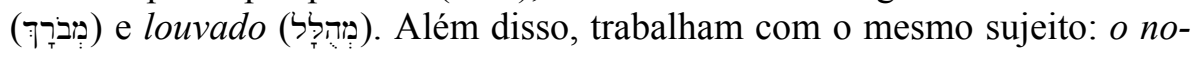
me do SENHOR. Com isso, continua a temática já desenvolvida em v. 1, onde se faz presente, igualmente, a expressão o nome do SENHOR. No caso do texto hebraico de v. 3b, o verbo seja - um "jussivo" com finalidade de indicar um desejo - "precisa ser pensado juntamente" com base no versículo

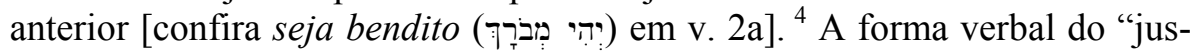
sivo" dá a entender que o serviço do louvor ainda pertence ao futuro.

Os elementos no centro da estrutura (v. 2b.3a) apresentam, por sua vez, algo surpreendente. Fala-se, de um lado, sobre a extensão temporal do louvor previsto: que o nome do SENHOR seja bendito desde agora e para sempre (v. 2). De outro lado, entra, junto com o aspecto temporal, a extensão espacial como conotação. Quer dizer: que o nome do SENHOR seja louvado do nascer do sol até seu poente (v. 3), ou seja, do Oriente ao Ocidente. Ambas as frases trabalham com o elemento estilístico do "merisma", sendo que uma realidade abrangente é apresentada, poeticamente, através de duas "porções". No caso, a expressão desde agora e para sempre (v. 2b) indica "o tempo inteiro", assim como do nascer do sol até seu poente (v. 3a) significa "em todo lugar". Promove-se, portanto, a ideia de que o louvor ao nome do SENHOR deva ganhar "extensões universais". 5

Entrementes, o S1 113 não menciona expressamente "Israel". Contudo, há duas referências a ele. A primeira encontra-se no uso do pronome possessivo em v. 5a: Quem é como o SENHOR, nosso Deus? Aqui se pronuncia alguém pertencente ao povo que tem o SENHOR como seu Deus. A segunda referência faz-se presente no uso da palavra povo (घ) em v. 8b. Comumente, nas Sagradas Escrituras, este substantivo é reservado a Israel, ao passo que o substantivo nações (a), também presente no Sl 113 - cf. v. 4a -, indica o conjunto dos povos não israelitas, ou seja, estrangeiros (cf. v. 4a). Afinal, "o salmo permanece neutro" em vista da relação entre o povo de Deus e as demais nações, pois "não toca em assuntos importantes apenas para Israel". 6

Ao olhar para o conjunto da primeira estrofe (v. 1b-3b), chama a atenção do leitor que a raiz louvar (הלל) aparece por três vezes (v. 1b.c.3b). Ao incluir v. 1a, escuta-se - logo no início, em pouco espaço e por três vezes (v. 1a.b.c) - a mesma ordem, através da presença do mesmo imperativo, no

\footnotetext{
${ }^{4}$ Klaus SeYbold, Poetik der Psalmen, p. 300.

${ }^{5}$ Frank-Lothar Hossfeld; Erich Zenger, Psalmen 101-150, p. 250.

${ }^{6}$ Gert Thomas Marthinus PRINSLOO, $\check{S}^{\mathbf{e}}, \hat{\mathbf{o l}} \rightarrow \mathbf{Y}^{\mathrm{e}}$ rûšsālayim $\leftarrow$ S̄āmayim: spatial orientation in the Egyptian Hallel (Psalms 113-118), p. 746.
} 


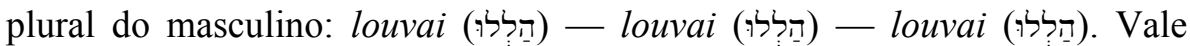
lembrar que este imperativo é repetido, outra vez, no final do poema (v. 9c): louvai (הללי). Mais ainda: no final da primeira estrofe (v. 3b) - como fecho que faz par com o início, formando uma inclusão —, a mesma raiz aparece outra vez, agora na forma do particípio passivo, no singular do masculino:

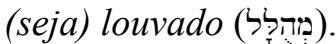

Outro paralelismo tríplice e, portanto, marcante para a primeira estrofe é formado pela expressão o nome do SENHOR (שם יהוה). Nas três ocasiões, o conjunto dos dois substantivos constitui o objeto do louvor ou da bendição. Veja a sequência: Louvai o nome do SENHOR! (v. 1b) - Seja bendito o nome do SENHOR! (v. 2a) - Seja louvado o nome do SENHOR! (v. 3b). Observando os verbos, vê-se uma estrutura concêntrica (A-B-A'). Além do mais, percebe-se que o nome do SENHOR marca presença em todas as frases da primeira estrofe.

Enfim, são as expressões repetidas que "apresentam o tema da estrofe e até do poema inteiro: o nome do SENHOR deve ser louvado". ${ }^{7}$ Mas por quem? O Salmo 113 menciona, logo no início, os servos do SENHOR (v. 1b) como agentes do louvor ao nome do SENHOR. Trata-se, comumente, de uma "referência aos que servem de forma leal, fiel e obediente ao SENHOR". 8 Neste sentido, o termo pode indicar Israel ou um determinado grupo neste povo, por exemplo, os servos do SENHOR que - na casa do SENHOR, em pé e durante as noites - são chamados a bendizer o SENHOR (S1 134,1). Ao se observar, porém, o contexto imediato, percebe-se que o louvor ao nome do SENHOR quer ganhar dimensões universais (cf. v. 2-3).

E por que o louvor ao nome do SENHOR é tão importante? Qual realidade indica? Em que sentido ganha importância para o povo de Deus e até universalmente? De certo, o próprio Salmo 113 terá que dizer algo sobre isso nas próximas duas estrofes.

Seja lembrado, no entanto, antes de conferir o contexto do próprio $\mathrm{Sl}$ 113, que, segundo as tradições bíblicas, a história da revelação do nome do SENHOR é atrelada, fundamentalmente, ao evento do êxodo. Moisés, pois, con-

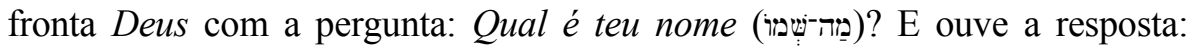
Serei quem serei! (אהיה אמשֶר אמהיה). Além de observar em Ex 3,14 uma semelhança entre o verbo ser (היה) e o "tetragrama", ou seja, as quatro letras que indicam o nome do Deus de Israel (יהוה) - aqui sempre apresentado como SENHOR -, é importante compreender a seguinte realidade: o SENHOR insiste,

\footnotetext{
${ }^{7}$ Gert Thomas Marthinus Prinsloo, Yahweh and the poor in Psalm 113: Literary motif and/or theological reality?, p. 469.

${ }^{8}$ Frank-Lothar Hossfeld; Erich ZENGER, Psalmen 101-150, p. 250.
} 
com sua resposta, na liberdade dele e em sua ação futura. Esta última revelará a seu povo quem ele é. No caso do êxodo, é a história da libertação do povo dos oprimidos da escravidão no Egito que indica o significado do nome do SENHOR e, com isso, as características fundamentais de sua vontade. ${ }^{9}$

\section{A soberania do SENHOR}

A segunda estrofe (v. 4-6) apresenta uma primeira justificativa para o louvor ao nome do SENHOR. Descreve-se agora a mais absoluta soberania do SENHOR. O poema insiste na contemplação da alteza e incomparabilidade do Deus de Israel. Mais ainda: medita-se sua capacidade de agir.

No nível da linguagem, tal soberania encontra-se realçada, por primeiro, pelo fato de o (nome do) SENHOR ocupar, na primeira estrofe (v. 1b-3b), a função de objeto (v. 1) ou de sujeito em frases passivas (v. 2-3), mas agora a função de sujeito. Quer dizer: é o SENHOR quem age na segunda estrofe. Também o acúmulo de particípios ativos, os quais descrevem as ações do SENHOR, em hebraico, como constantes, chama a atenção do leitor. Neste sentido, o SENHOR é quem se eleva (v. 4a), quem se enaltece (v. 5b) e quem se abaixa (v. 6a). Mais tarde, na terceira estrofe, os particípios ativos continuam: é o SENHOR quem levanta (v. 7a) e quem deixa assentar-se (v. 9a).

A primeira afirmação na segunda estrofe destaca a superioridade do Deus de Israel em relação aos povos não israelitas: é o SENHOR quem se eleva sobre as nações (v. 4a). De certo, a história do antigo Israel acontece em meio a outras nações (ấ. (ג). Em diversas épocas, estas últimas chegam a formar impérios, estendendo seu poder para além de suas fronteiras tradicionais. Por isso, Israel vê sua sobrevivência ameaçada. Consequentemente, lamenta: Todas as nações me circuncidaram (S1 118,10a). Mesmo assim, Israel insiste na seguinte possibilidade: Em nome do SENHOR, as repilo (S1 118,10b-c). Mais ainda: em vez de as nações poderem satirizar Israel Onde está o Deus deles? (S1 115,2) —, irão escutar de novo, após revelar-se a superioridade do Deus de Israel, a ordem que vale universalmente: Louvai o SENHOR, ó todas as nações! (Sl 117,1).

Seguindo as palavras de v. 4, surge um interessante paralelismo entre

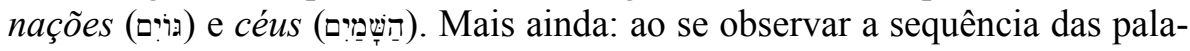
vras no texto hebraico, torna-se visível outra estrutura concêntrica em forma de "quiasmo", desta vez com um centro formado por um elemento só:

\footnotetext{
${ }^{9}$ A respeito de Ex 3,14, cf. Georg Fischer, Jahwe unser Gott. Sprache, Aufbau und Erzähltechnik in der Berufung des Mose (Ex 3-4), p. 147-154.
} 


$\begin{array}{lc}\text { v. 4a: } & \text { Quem se eleva } \\ \text { v. 4a: } & \text { sobre todas as nações } \\ \text { v. 4a: } & \text { é o SENHOR, } \\ \text { v. 4b: } & \text { sobre os céus } \\ \text { v. 4b: } & \text { está sua glória. }{ }^{10}\end{array}$

O leitor é convidado a contemplar a superioridade do SENHOR, sendo que o Sl 113 parte da ideia de Deus elevar-se sobre as nações. Com isso, Deus eleva-se sobre a terra (cf. Sl 46,11). Mais ainda: tem-se a conotação de que o $S E N H O R$, ao se elevar sobre todos os povos, revela sua realeza (S1 99,12). Somente em seguida, afirma-se que a glória do SENHOR está também sobre os céus. Com isso, inverte-se a sequência do pensamento de que Deus se eleva sobre os céus e, assim, sua glória está sobre a terra (cf. Sl 57,6.12; $108,6)$. Contudo, não tem como criar uma lógica interna ou uma determinada sequência em relação à questão da superioridade de Deus, pois a majestade do SENHOR está, sempre e de forma simultânea, sobre os céus e a terra (cf. S1 148,13).

Segue-se uma "pergunta retórica em v. 5-6 que destaca a singularidade incomparável de Deus [...], criando uma relação entre a incomparabilidade e o espaço do universo, ou seja, céus e terra". ${ }^{11}$ A frase é de difícil compreensão, pois se pode suspeitar de uma inversão da ordem natural das palavras na oração, chamada de "hipérbato". Além disso, pode ser descoberto outro "quiasmo":

$\begin{array}{lr}\text { v. 5a: } & \text { Quem é como o SENHOR, nosso Deus - } \\ \text { v. 5b: } & \text { que se enaltece para assentar-se } \\ \text { v. 6a: } & \text { e se abaixa para ver - } \\ \text { v. 6b: } & \text { nos céus e na terra? }\end{array}$

No caso, os dois elementos exteriores (v. 5a.6b) parecem "constituir uma unidade sintática e semântica": Quem é como o Senhor, nosso Deus, nos céus e na terra? ${ }^{12}$ Tal unidade, por sua vez, encontra-se interrompida por dois elementos paralelos no centro (v. 5b.6a): neles, o SENHOR é descrito como quem se enaltece para assentar-se - particípio ativo, no singular do masculino (Hifil), seguido por um infinitivo introduzido pela preposição para (ל) - $\mathrm{e}$ como quem se abaixa para ver - outro particípio ativo, no singular do masculino (Hifil), novamente seguido por um infinitivo introduzido pela preposição para (ל). Contudo, v. $6 \mathrm{~b}$ pode ganhar seu ponto de referência também em

\footnotetext{
${ }^{10}$ Cf. Gert Thomas Marthinus PrInSLOO, Yahweh and the poor in Psalm 113, p. 471.

${ }^{11}$ Frank-Lothar Hossfeld; Erich ZeNGER, Psalmen 101-150, p. 251.

${ }^{12}$ Gert Thomas Marthinus PrinsLoO, Yahweh and the poor in Psalm 113, p. 471.
} 
v. 5b.6a, no sentido de Deus se enaltecer nos céus para assentar-se e se abaixar para ver na terra. ${ }^{13}$ Um texto poético como o Sl 113 talvez queira criar uma ambiguidade como esta em v. 6b, justamente para envolver seus leitores até o extremo na busca do provável sentido do texto.

Em todo caso, surge "uma tensão quase que paradoxal em vista das atividades com as quais o SENHOR preenche o espaço: de um lado, trona no alto, de outro lado, abaixa-se para ver". ${ }^{14} \mathrm{Ou}$, com outras palavras: "A polaridade faz parte da natureza do SENHOR", no sentido que "sua majestade se manifesta em sua vontade de abaixar-se a partir dos céus, a fim de ver suas criaturas, que estão na terra". 15

\section{A concretização da soberania de Deus na vida dos pobres}

A terceira estrofe (v. 7a-9b) concretiza a questão de quem está sendo visto por Deus, quando este se abaixa. Neste sentido, "dentro do comportamento normativo do SENHOR, sua atuação para com os pobres torna-se central; [...] em vez de compaixão e caridade em relação aos pobres, o SENHOR provoca uma inversão das hierarquias sociais". ${ }^{16} \mathrm{Ou}$, com outras palavras: "Justamente como Deus, cuja soberania inclui alteza e baixeza, o nascer do sol e seu poente, todas as nações e todo o tempo, dirige-se àqueles que, em termos sociais, estão num submundo e os deixa fazer parte da casa viva de sua criação, a qual domina como rei". 17

Também a terceira estrofe traz formulações poéticas. Alguns elementos estilísticos somente podem ser vistos se mantida a sequência das palavras do texto hebraico:

$\begin{array}{ll}\text { v.7a: } & \text { É quem levanta, do pó, o necessitado: } \\ \text { v.7b: } & \text { do lixo, eleva o pobre, } \\ \text { v. 8a: } & \text { a fim de fazê-lo assentar-se junto aos nobres, } \\ \text { v. 8b: } & \text { junto aos nobres do povo dele. }\end{array}$

Três paralelismos unem as duas frases em v. 7: quem levanta (v. 7a) e eleva (v. 7b), pó (v. 7a) e lixo (v. 7b), o necessitado (v. 7a) e o pobre (v. 7b). Em relação aos sujeitos-predicados - quem levanta (v. 7a) e eleva (v. 7b) e aos complementos deles — do pó (v. 7a) e do lixo (v. 7b) —, faz-se presente

\footnotetext{
${ }^{13}$ Veja a discussão em Joachim BECKER, Einige Hyberbata im Alten Testament, p. 257-263.

${ }^{14}$ Frank-Lothar Hossfeld; Erich ZENGER, Psalmen 101-150, p. 251.

${ }^{15}$ Gert Thomas Marthinus PrinsLoO, Yahweh and the poor in Psalm 113, p. 471.

${ }^{16}$ Frank-Lothar Hossfeld, Der gnädige Gott und der arme Gerechte. Anthropologische Akzente in der Psalmengruppe 111-118, 57.

${ }^{17}$ Erich ZENGER, Götter- und Götterbildpolemik in Ps 112-113 LXX = Ps 113-115 MT, p. 246.
} 
um "quiasmo", sendo que os elementos encontram-se colocados de forma invertida na formulação paralela. Assim, a ação de Deus ganha, literariamente, maior destaque. Os objetos diretos ocupam, nas duas frases, a última posição: cf. o necessitado (אבריו) e o pobre (אביון) como dupla em S1 72,13 e 84,4.

O "propósito da ação do SENHOR é indicado em v. 8, através de uma construção que trabalha com a preposição a fim de ou para (ל), mais o verbo no infinitivo". ${ }^{18}$ Novamente, observa-se um paralelismo, desta vez em forma de uma "anadiplose", sendo que a última expressão da unidade literária anterior - cf. junto aos nobres em v. 9a - é repetida no começo da unidade seguinte - cf. junto aos nobres do povo dele em v. $9 \mathrm{~b}-$; de certo, o elemento estilístico "dá ênfase à inversão total do destino" dos pobres e necessitados. ${ }^{19}$

$\mathrm{Na}$ última frase da terceira estrofe (v. 9), o poema insiste na mesma lógica interna, já desenvolvida em v. 7-8. De novo, Deus age, a fim de inverter o destino de outra personagem que representa os mais necessitados. Contudo, desta vez, se fala, expressamente, de uma mulher sofrida:

$$
\begin{aligned}
& \text { v. 9a: É quem faz assentar-se a estéril da casa, } \\
& \text { v. 9b: como alegre mãe de filhos. }
\end{aligned}
$$

O paralelismo nasce, desta vez, de uma oposição: cf. a estéril (עִקר) em v. 9a e a mãe (אם) em v. 9b. Além disso, escuta-se, no hebraico, uma "aliteração", quer dizer, uma pronúncia semelhante entre as expressões $d a$

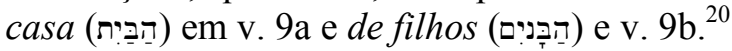

Enfim, a terceira estrofe "concretiza a essência de Deus em seu comportamento social". ${ }^{21}$ Isso se torna, literariamente, visível, quando se observa a repetição de determinados verbos, os quais ora descrevem a ação de Deus em relação a si mesmo ora sua ação em relação aos mais necessitados, invertendo o destino deles. Veja os dois casos: como o SENHOR se enaltece para assentar-se (לָָָָׁת) (v. 5b), ele também faz assentar-se o pobre junto aos nobres (v. 7b.8a) e a estéril da casa como alegre mãe de filhos: cf. o uso da

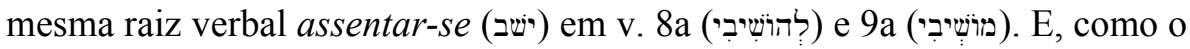
SENHOR se eleva (רָ) sobre todas as nações (v. 4a), ele eleva (יריָ) também o pobre do lixo (v. $7 \mathrm{~b})$.

\footnotetext{
${ }^{18}$ Gert Thomas Marthinus Prinsloo, Yahweh and the poor in Psalm 113, p. 472. O pronome $o$ na expressão fazê-lo não existe no texto hebraico. Contudo, já foi introduzido na tradução da Septuaginta, ao se traduzir o texto hebraico para o grego.

${ }^{19}$ Gert Thomas Marthinus PrInSLOO, Yahweh and the poor in Psalm 113, p. 472.

${ }^{20} \mathrm{Cf}$. Gert Thomas Marthinus PrinsLOO, Yahweh and the poor in Psalm 113, p. 472s.

${ }^{21}$ Frank-Lothar Hossfeld; Erich ZENGER, Psalmen 101-150, p. 252.
} 


\section{Resultados}

O Salmo 113 gira em torno do próprio SENHOR Deus. O nome do Deus de Israel é mencionado por "oito" vezes no poema: cf. a palavra $S E$ NHOR (יהוה) em v. 1a.b.c.2a.3b.4a.5a.9c. São "sete mais um". Se "sete" trouxer a conotação de algo perfeito, então, "sete mais um" indica algo mais que perfeito. Por três vezes (v. 1c.2a.3b), fala-se, de forma expressa, do nome do SENHOR (שם יהוה). Enfim, a questão é: Quem é como o SENHOR, nosso Deus? (v. 5a). Eis a pergunta que ocupa o centro do texto. Mais ainda: somente nesta pergunta retórica, o nome de Deus, SENHOR (יהוה), é acompanhado pela palavra Deus, mais exatamente, nosso Deus (אלהינוּ).

A lógica interna proposta pelo S1 113, em termos teológicos, parece ser bastante simples. Nos dois elementos da moldura (v. 1a.9c) e na primeira estrofe (v. 1b-3b), promove-se o convite de louvar o SENHOR, respectivamente, de louvar o nome do SENHOR. Tal louvor deve perpassar os tempos - desde agora e para sempre (v. 2b) — e incluir todos os lugares, do leste ao oeste - ou seja, do nascer do sol até seu poente (v. 3a). Quer dizer, por mais que o movimento do louvor ao nome do SENHOR comece com Israel, a ideia é que ganhe dimensões universais.

A razão do louvor ao nome do SENHOR encontra-se na soberania deste Deus, contemplada na segunda estrofe do poema (cf. v. 4-6). O SENHOR está acima de todas as nações (v. 4a) e até acima dos céus (v. 4b). Ou seja: imagina-se a mais absoluta superioridade e incomparabilidade deste Deus. Contudo, sua alteza (v. 5b) e, com isso, sua transcendência não impedem sua aproximação ao que existe nos céus e, de modo especial, a quem está na terra (cf. v. 6b). Afinal, o homem pertence à terra e somente pode imaginar a glória de quem está sobre os céus (v. 4b) à medida que o SENHOR se abaixe e lhe revele sua glória, confrontando-se com a realidade que na terra se faz presente (v. 6a).

Justamente esta ação reveladora de Deus ao homem é o tema da terceira estrofe (v. 7a-9b). O poema chega a seu ponto culminante. Ganha exclusividade agora o assunto de o SENHOR agir a favor dos pobres, provocando a inversão total do destino deles. Neste sentido, o S1 113 insere-se no meio de outras tradições bíblicas que insistem na mesma reflexão. Sejam lembradas as tradições do êxodo - experiência fundadora da religião do Antigo Israel -, quando prevêem a saída dos oprimidos do Egito cobertos de bens, bens que, anteriormente, pertenceram aos opressores (cf. Ex 3,2122). Além disso, seja mencionado, sobretudo, o Cântico de Ana (1Sm 2,110), texto ao qual o S1 113 revela maior proximidade literária. Também Ana 
imagina que o SENHOR levante o fraco do pó e eleve o pobre do lixo (1Sm 2,8), além da estéril dar à luz sete vezes ( $1 \mathrm{Sm} 2,5)$.

Enfim, o Sl 113 convida seus leitores a dirigirem sua atenção à história de vida dos mais necessitados. Eis a oportunidade de descobrir a ação de Deus neste mundo. Existe, pois, a experiência surpreendente de oprimidos recuperarem sua liberdade, de humilhados se reencontrarem com sua dignidade e de injustiçados receberem justiça, mesmo que o homem falhe, repetidamente, diante da tarefa de tornar-se solidário com os mais sofridos. Portanto, em todos estes casos de uma inversão feliz do destino dos miseráveis, é oportuno perguntar-se se não foi o SENHOR quem ergueu o pobre da miséria $($ Sl 107,41).

\section{Referências Bibliográficas}

BECKER, Joachim. Einige Hyberbata im Alten Testament. In: Biblische Zeitschrift, n. 17, a. 1973, p. 257-263.

FISCHER, Georg. Jahwe unser Gott. Sprache, Aufbau und Erzähltechnik in der Berufung des Mose (Ex 3-4), Göttingen, Vandenhoeck \& Ruprecht, 1989. (Coleção: Orbis Biblicus et Orientalis, 91).

HOSSFELD, Frank-Lothar. Der gnädige Gott und der arme Gerechte: Anthropologische Akzente in der Psalmengruppe 111-118. In: Christoph BÖTTINGHEIMER; Hubert FILSER. Kircheneinheit und Weltverantwortung. Regensburg, Pustet, 2006. (FS Peter NEUNER).

HOSSFELD, Frank-Lothar; ZENGER, Erich. Psalmen 101-150. Freiburg, Herder, 2008. (Coleção: Herders Theologischer Kommentar zum Alten Testament).

PRINSLOO, Gert Thomas Marthinus. Yahweh and the poor in Psalm 113: Literary motif and/or theological reality? In: Old Testament Essays, n. 9, a. 1996, p. 465-485. (Journal of the Old Testament Society of South Africa).

PRINSLOO, Gert Thomas Marthinus. ŠS ${ }^{e}$ ôl $\rightarrow$ Y rûšālayim $\leftarrow$ Šāmayim: Spatial orientation in the Egyptian Hallel (Psalms 113-118). In: Old Testament Essays, n. 19/2, a. 2006, p. 739-760. (Journal of the Old Testament Society of South Africa).

SCHRÖTEN, Jutta. Entstehung, Komposition und Wirkungsgeschichte des 118. Psalms. Weinheim, Beltz Athenäum, 1995.

SEYBOLD, Klaus. Poetik der Psalmen. Stuttgart, Kohlhammer, 2003.

ZENGER, Erich e outros. Einleitung in das Alte Testament. $7^{\mathrm{a}}$ ed. Stuttgart, Kolhammer, 2008. [Em português, existe a tradução da primeira edi- 
ção deste livro: ZENGER, Erich. Introdução ao Antigo Testamento. São Paulo, Loyola, 2003].

ZENGER, Erich. Götter- und Götterbildpolemik in Ps 112-113 LXX = Ps

113-115 MT. In: Erich ZENGER (org.). Der Septuaginta-Psalter:

Sprachliche und theologische Aspekte. Freiburg, Herder, 2001. (Coleção: Herders Biblische Studien, 32).

\section{Resumo}

Este artigo dedica-se à descrição da beleza literária e das afirmações teológicas do Salmo 113. A lógica interna deste Salmo pode ser descrita da seguinte forma: um convite ao louvor do nome do SENHOR (v. 1-3) é justificado com a reflexão sobre a superioridade absoluta e incomparabilidade dele (v. 4-6). Tais características do Deus de Israel, por sua vez, podem ser compreendidas pelo ser humano, quando se contempla a atuação do SENHOR em favor dos pobres, sendo que o destino deles é invertido de forma dramática (v. 7-9).

Palavras-chave: Salmos, Espiritualidade Bíblica, Ação de Deus, Pobres.

\section{Zusammenfassung}

Dieser Aufsatz widmet sich der Beschreibung der literarischen Schönheit und der theolgischen Aussagen des 113. Psalms. Die innere Logik dieses Psalms kann folgendermassen beschrieben werden: eine Aufforderung zum Lob des Namens des Gottes Israels (v. 1-3) wird mit dem Hinweis auf dessen absolute Überlegenheit und Unvergleichbarkeit begründet (v. 4-6). Letztere können jedoch gerade dann vom Menschen wahrgenommen werden, wenn dieser Gott sich den Armen mit dem Ziel zuwendet, deren Lebenssituation in dramatischer Weise umzukehren (v. 7-9).

Stichwörter: Psalmen, biblische Spiritualität, Handeln Gottes, Arme.

Matthias Grenzer

Doutor em Teologia Bíblica pela Faculdade de Teologia

St. Georgen dos Jesuítas em Frankfurt, Alemanha.

Leciona na Faculdade de Teologia da PUC de São Paulo.

Artigo Recebido em 06/10/2010

Artigo Aprovado em 08/11/2010 